\title{
GEOGRAPHIC DIFFERENTIALS IN THE RATE OF RETURN ON SA VINGS AND LOAN ASSETS
}

\author{
Richard J. Cebula*
}

\begin{abstract}
Based on a constrained S\&L profit-maximization model, this empirical study estimates six reduced-form equations, using a heteroskedasticity correction, to identify the factors influencing the rate of return on S\&L assets. For the years 1988 and 1989, the results consistently imply that the rate of return on S\&L assets is an increasing function of the mortgage rate, the percentage of gross state product (GSP) deriving from manufacturing, and the capitaVasset ratio. In addition, it appears that the rate of return on S\&L assets is a decreasing function of the volatility of gross state product, the cost of deposits, and very high mortgage delinquency rates.
\end{abstract}

\section{INTRODUCTION}

The closing (failure) rate of savings and loan institutions (S\&Ls) has received widespread attention in recent years, not only in the popular press but also in the scholarly literature. While the popular press has focused extensively on the numbers of failures, the resolution costs of S\&L closings to the taxpayers, and certain allegations of fraudulent behavior on the part of at least some S\&L directors and officers, the scholarly literature has focused more on the apparent causes of those closings--at least in part with the objective of helping to avert such closings in the future.

Much of the research literature has focused on the role of federal deposit insurance in the S\&L failure rate. Indeed, in a widely acclaimed study by Barth (1991, p. 101), it is convincingly argued that ". . federal deposit insurance was the unifying cause of the savings and loan disaster." Barth (1991, pp. 100-101) argues that federal deposit insurance has encouraged the S\&Ls to take on additional risk and that in so doing has significantly contributed to the rate of S\&L failures. Barth (1991, p. 100) charges that ". . the very availability of such insurance enabled many inadequately capitalized savings and loans to engage in high-risk activities and to gamble for resurrection." Many other studies, including those by Brumbaugh (1988), Barth and Brumbaugh (1992), and Kane (1985; 1982), have previously made similar arguments.

But federal deposit insurance is by no means viewed as the only significant cause of S\&L closings over time. Such factors as the 1981-82 recession, rising interest rates, increased interest rate volatility, declining capital-to-asset ratios,

\footnotetext{
-Professor of Economics, Georgia Institute of Technology.
} 
declining crude oil prices, and the Tax Reform Act of 1986 are all viewed as contributing to the S\&L crisis. In fact, the recent study by Cebula (1993) provides empirical support that all of these factors impacted on the S\&L closing rate.

Yet another dimension of the S\&L failure problem is the geographic variation in the S\&L failure rate. Amos (1992) has recently investigated determinants of interstate differentials in the commercial bank closing rate, focusing principally on interstate differences in the growth rate of GSP, the volatility of GSP, the percentage of GSP deriving from manufacturing, from agriculture, or from oil and natural gas extraction, and other factors. Using Amos (1992) as a point of departure, Cebula (1994) has expanded the scope of inquiry into interstate differentials in commercial bank closings to include a variety of money market (and other) factors, such as the cost of funds and capital-to-asset ratios and the extent to which interstate banking is permitted. Finally, depending to some extent on the Amos (1992) study and extensively on the Barth (1991) study, Chou, Cebula, and Schaffer (1994) use the heteroskedastic-TOBIT model to investigate the determinants of geographic differentials in the S\&L closing rate for the 1982-1988 period. The exploratory analysis in Chou, Cebula, and Schaffer (1994) finds that the S\&L closing rate differential across states principally is determined by the rate of return on S\&L assets, the inflation rate of housing prices, and a variety of political factors.

While the empirical literature has focused on S\&L closings per se, it has at the aggregative (state or national) level failed to formally investigate the determinants of the S\&L rate of return that so intimately underlies and is so closely associated with the S\&L closing rate. Accordingly, the present study seeks to extend the inquiry into the S\&L closing problem by examining, at the state level, the determinants of geographic differentials in rate of return on S\&L assets. Clearly, if the rate of return on S\&L assets declines sharply and becomes negative, as it so often has over the years since 1980, then an extended experience of such negative rates of return may ultimately doom the affected S\&L institutions to eventual insolvency. In seeking to identify the key factors causing interstate differentials in the rate of return on S\&L assets, it is hoped that further insights into the factors that influence S\&L economic health will be gained so that poor rates of return on S\&L assets can perhaps be ameliorated in the future.

Section II provides a simple model of constrained profit maximization for S\&Ls. Based largely on this model, the empirical analysis in section III seeks to provide concrete evidence on the determinants of geographic differentials in the rate of return on S\&L assets. Section IV provides two additional empirical estimations. Finally, section $\mathrm{V}$ provides conclusions. 


\section{MODEL}

In basic terms, the S\&L is treated as a profit-maximizing, rate- (price-) taking firm. The S\&L generates revenues principally through the issuance of mortgage loans and non-mortgage loans to the nonbank public and from the purchase of various government securities. ${ }^{1}$ Although non-mortgage loans and government securities are important sources of revenues, mortgage loans are nevertheless the dominant source of S\&L revenues. The S\&L obtains funds to support these loans and security purchases principally through the deposit markets, although some funds are obtained from various outside sources of borrowings. The S\&L's total costs are the sum of its total payments for deposits (which principally include explicit interest costs and deposit insurance premiums), ${ }^{2}$ the net interest payments for outside borrowed funds, and operating costs. Each S\&L is constrained in the sense that (1) its total volume of mortgage and non-mortgage loans outstanding plus its total security holdings cannot exceed the sum of its excess reserves plus net outside funds borrowed plus net worth and (2) that its required capital-(net worth-) to-asset ratio cannot fall below a certain regulatory value (denoted as " $\mathrm{Z}$ " in the model below).

Within this framework, the S\&L's profit maximization can be described, as follows:

MAXIMIZE:

PROFIT $=r M^{*}$ MORT*(1-PML) + rNM*NMORT*(1-PNML)

$+\mathrm{rS} * \mathrm{SEC}-(\mathrm{rE}+\mathrm{IP}) * \mathrm{DEP}-\mathrm{rO} * \mathrm{OUT}-\mathrm{C}(\mathrm{MORT}, \mathrm{NMORT}$,

SEC, DEP, OUT)

SUBJECT TO:

$\mathrm{MORT}+\mathrm{NMORT}+\mathrm{SEC}=(1-\mathrm{RR}) * \mathrm{DEP}+\mathrm{OUT}+\mathrm{NW} ; 1>\mathrm{RR}>0$

NW/ASSET $\geq Z ; \quad 1>Z>0$

where:

PROFIT = net profit for the S\&L

MORT = outstanding S\&L mortgage loans

$\mathrm{rM}$

$=$ the average interest rate payable on outstanding mortgage loans at the S\&L 


\begin{tabular}{|c|c|c|}
\hline PML & $=$ & $\begin{array}{l}\text { the percentage of the S\&L's mortgage loans that is not } \\
\text { "performing" }\end{array}$ \\
\hline NMORT & $=$ & outstanding non-mortgage loans at the S\&L \\
\hline $\mathrm{rNM}$ & $=$ & $\begin{array}{l}\text { the average interest rate payable on the non-mortgage loans } \\
\text { at the S\&L }\end{array}$ \\
\hline PNML & $=$ & $\begin{array}{l}\text { the percentage of the S\&L's non-mortgage loans that is not } \\
\text { performing }\end{array}$ \\
\hline SEC & $=$ & the S\&L's government security holdings \\
\hline $\mathrm{rS}$ & $=$ & $\begin{array}{l}\text { the average interest rate paid on the S\&L's government } \\
\text { security holdings }\end{array}$ \\
\hline DEP & $=$ & the S\&L's deposit liabilities \\
\hline $\mathrm{rE}$ & $=$ & $\begin{array}{l}\text { the average explicit interest rate on the S\&L's deposit } \\
\text { liabilities }\end{array}$ \\
\hline IP & $=$ & the deposit insurance premium \\
\hline RR & $=$ & reserve requirement \\
\hline OUT & $=$ & net funds borrowed from the outside \\
\hline ro & $=$ & $\begin{array}{l}\text { the average interest rate paid on net funds borrowed from } \\
\text { the outside }\end{array}$ \\
\hline$C()$ & $=$ & the S\&L's factor and implicit cost function \\
\hline NW & $=$ & the S\&L's net worth \\
\hline ASSET & $=$ & value of the S\&L's assets \\
\hline $\mathrm{Z}$ & $=$ & the required ratio of net worth to assets \\
\hline
\end{tabular}

As a practical matter, although non-mortgage loans as a percentage of total S\&L assets rose significantly (nearly 400 percent) over the period from 1979 (the year prior to 1980, when in March the Depository Institutions Deregulation and Monetary Control Act, DIDMCA, was implemented) until 1989 (the most recent year for which all the data needed for our study were available), the fact remains that-even in 1989-non-mortgage loans composed barely 9 percent of total S\&L assets. Thus, even in recent times mortgage loans comprise the major form of S\&L assets and the predominant revenue source for S\&Ls. Hence, in our analysis, we shall focus primarily on mortgages as the revenue source affecting the rate of return (profit rate) on $\mathrm{S} \& \mathrm{~L}$ assets.

Accordingly, on the revenue side, it is clear that S\&L profits should significantly depend on the mortgage interest rate charged (rM) and the proportion of S\&L mortgage loans that is not performing (PML). The factors that influence PML are largely those that reflect risk dimensions of the mortgage loans outstanding. A number of quantifiable and measurable factors have been argued in the literature to influence this basic dimension of mortgage portfolio risk. Based on arguments in Amos (1992), Barth (1991), and Chou, Cebula, and Schaffer (1994), 
we would expect that at the state level PML may be a function of (1) the stability of the state's economy, (2) the state's economic base, and (3) the propensity for S\&L directors and officers within the state to pursue low-risk lending strategies.

It is argued that the more unstable a state's economy, the greater the likelihood of mortgage (as well as other loan) nonperformance (delinquency or default) within a state. Following Amos (1992), Barth (1991), and Chou, Cebula, and Schaffer (1994), we adopt the variance in the average percentage growth rate of gross state product (VGSP) to measure instability of the state's economy. Presumably, PML is an increasing function of VGSP.

Next, as noted expressly in Amos (1992) and Barth (1991), the economic base of the state may influence the susceptibility of loans to nonperformance risk. Clearly, the greater the dependence of a state's economy on a stable and prospering industry base, the lower the loan nonperformance risk. Following Amos (1992), we adopt the variable MAN, the percentage of gross state product deriving from manufacturing, to measure the economic base effect. Alternative measures of the economic base were systematically considered, such as the percentage of gross state product deriving from oil and natural gas extraction (PGSPONGE) or from agriculture (PGSPAG). Indeed, experimentation with these three economic base measures (MAN, PGSPONGE, and PGSPAG) reveals that (a) use of more than one of these variables at a time is problematic due to severe multicollinearity problems; (b) the variables MAN and PGSPONGE perform comparably when included in the estimations one at a time, but variable MAN is much less highly correlated with the other explanatory variables in the system than PGSPONGE; and (c) the variable PGSPAG performs very poorly when included in the model regardless of the presence of MAN and/or PGSPONGE while at the same time presenting multicollinearity problems for several other explanatory variables. For simplicity, then, we proceed with the variable MAN and hypothesize variable MAN to be the economic base measure most likely to increase the likelihood of loan performance.

Finally, as emphasized in Barth (1991), the higher the ratio of S\&L net worth to assets, the better (the more responsibly) managed S\&Ls tend to be, because management engages in less risky activities and concentrates instead on those activities with which it is more experienced, more knowledgeable, better trained, and more expert. Alternatively expressed, the higher the ratio of S\&L net worthto-assets (NW/ASSET), the greater the likelihood that the S\&L will adopt prudent and risk-averse lending and other related practices. Ultimately, this is because the higher the capital-to-asset ratio, the greater the incentive for such behavior in order for management to protect (preserve) the owners' capital. Conversely, with very low (NW/ASSET) values, the incentive exists to venture into endeavors which tend to be riskier and beyond the expertise of S\&L management [Barth 
(1991)]. Therefore, the higher the capital/asset ratio, the greater the likelihood that mortgage loans, as well as non-mortgage loans and other activities, will perform well.

On the cost side of the profit picture, we observe first that the implementation of risk-related deposit insurance premiums under the Federal Deposit Insurance Corporation Improvement Act of 1991 (FDICIA), came years after the data set examined in this study. As a result, IP was-in the principal year of our study, 1988-uniform across all S\&Ls; therefore, since there is no geographic differential in IP in 1988, this factor is ignored in this study. Moreover, since outside borrowing (OUT) is a relatively small source of funds to S\&Ls in 1988 (roughly 9 percent of total S\&L funds) and since interstate differentials in the volume of outside borrowing (OUT) and in the cost thereof (rOUT) are relatively minor, we also ignore these items in our study.

On the other hand, interstate differentials in the cost of deposits at S\&Ls, rE, are quite substantial. In 1988, for example, the range between the lowest and highest state averages on the S\&L cost of deposits was 6.27 percent (West Virginia) to 7.84 percent (Kansas and Texas). Moreover, since deposits are the primary source of funds to $S \& L s, r E$ cannot be ignored. Based on the profit equation (1) above, it follows that the rate of return (profit) on S\&L assets should be a decreasing function of $r E$.

Based on the various arguments expressed above, it follows that the rate of return on $S \& L$ assets (RET), as a proxy for the $S \& L$ profit rate, is described by

RET $\quad \mathrm{f}(\mathrm{rM}$, VGSP, MAN, NW/ASSET, $\mathrm{rE})$

where it is hypothesized that:

$\mathrm{f}_{\mathrm{rM}}>0, \mathrm{fVGSP}<0, \mathrm{f}_{\mathrm{MAN}}>0, \mathrm{f}_{\text {NW/ASSET }}>0, \mathrm{f}_{\mathrm{rE}}<0$

\section{EMPIRICAL ESTIMATES}

Based on the model expressed in equations (4) and (5), we estimate the following reduced-form equations:

$\begin{array}{ll}\text { RETs } & =a_{0}+a_{1} \mathrm{rMs}+\mathrm{a}_{2} \text { VGSPs }+\mathrm{a}_{3} \text { MANs }+\mathrm{a}_{4} \text { (NW/ASSET) } \\ & +\mathrm{a}_{5} \mathrm{rEs}+\mathrm{u} \\ \text { RETs } & =\mathrm{b}_{0}+\mathrm{b}_{1} \mathrm{rMs}+\mathrm{b}_{2} \text { VGSPs }+\mathrm{b}_{3} \text { (NW/ASSET) } \\ & +\mathrm{b}_{4} \mathrm{rEs}+\mathrm{u}^{\prime}\end{array}$ 
RETs

RETs $=c_{0}+c_{1} \mathrm{rMs}+\mathrm{c}_{2}$ MANs $+\mathrm{c}_{3}$ (NW/ASSET)s

$+\mathrm{c}_{4} \mathrm{rEs}+\mathrm{u}^{\prime \prime}$

$=\mathrm{d}_{0}+\mathrm{d}_{1} \mathrm{rMs}+\mathrm{d}_{2}$ VGSPs $+\mathrm{d}_{3}$ MANs $+\mathrm{d}_{4}$ (NW/ASSET) $s$

$+d_{5}$ rEs + d6 HIDELs + $u^{\prime \prime \prime}$

where:

RETs = average rate of return on S\&L assets in state s, 1988, as a percent per annum

$\mathrm{a}, \mathrm{b}_{0}, \mathrm{c}_{0}, \mathrm{~d}_{0}=$ constants

rMs $\quad=$ the average mortgage portfolio yield at S\&Ls in state s, 1988, as a percent per annum

VGSPs $=$ the variance in the percentage average growth rate of gross state product in state s, 1979-1988, as a measure of economic instability in state $s$

MANs $\quad=$ the percentage of gross state product in state $s$ that derived from manufacturing, 1988

(NW/ASSET)s $=$ the average ratio of regulatory capital to assets at S\&Ls in state s, 1988, expressed as a percent

$\mathrm{rE}$

$=$ the average cost of deposits at S\&Ls in state s, 1988, as a percent per annum

HIDELs = a dummy (binary) variable indicating states that had a delinquency rate of 10 percent or more on their S\&L mortgage loans in 1988; HIDELs $=1$ for those state where the delinquency rate on S\&L-owned mortgage loans was 10 percent or more and HIDELs $=0$ otherwise $u, u^{\prime}, u^{\prime \prime}, u^{\prime \prime \prime}=$ stochastic error terms.

We focus initially on 1988 for three reasons. First, 1988 was the year having by far the highest number of S\&L closings of the entire 1980s decade. Second, 1988 is the most recent year during which a large number of S\&L failures was experienced and for which all of the necessary data for this study were also available. Third, the year 1988 may also be of special interest because the total assets of failed thrifts during 1988 exceeded that of any other year ( 100.7 billion current dollars). These observations notwithstanding, in the next section of this study, we shall estimate the basic model for the year 1989. The data source for RETs, rMs, (NW/ASSET)s, rEs, and for determining HIDELs was the Office of Thrift Supervision (1989); the data source for MANs and for computing VGSPs was the Bureau of Economic Analysis. It should be noted that our estimated coefficients change very little and that our basic conclusions are unchanged if we use the 
average ratio of tangible capital to assets (TAP) rather than the average ratio of regulatory capital to assets (RAP) to measure (NW/ASSET). In any case, we contend that the issue of RAP versus TAP is nevertheless beyond the scope of this study.

Table 1 provides the means and variances for the variables in the system. Specifically, the means and variances corresponding to variables RETs, rMs, VGSPs, MANs, (NW/ASSET)s, and rEs, as well as the S\&L failure rate, SLFRs (S\&L closings in state $s$ as a percent of the total number of S\&Ls in state $s$ ), across states are shown in the table. Clearly, in most cases for the variables in our model, there is a considerable variation in each variable across states. In addition, as Chou, Cebula, and Schaffer (1994) find and Table 1 confirms, there is an extremely wide variation across states in the $S \& L$ closing rate.

Equation (6) includes all of the factors summarized in equations (4) and (5). Equation (7) excludes variable MANs [from equation (6)] whereas equation (8)

TABLE 1

Means and Variances

\begin{tabular}{lrrrrrrr}
\hline \hline Variable: & VGSPs & rEs & rMs & (NW/ASSET)s & SLFRs & RETs & MANs \\
\hline & & & & & & & \\
Mean: & 15 & 7.99 & 11.86 & 3.2 & 4.1 & -1.08 & 18.6 \\
Variance: & 361 & 0.103 & 0.17 & 0.64 & 21.5 & 0.314 & 82.8 \\
\hline
\end{tabular}

excludes variable VGSPs [from equation (6)], so as to demonstrate the resiliency of the basic model. Finally, equation (9) includes all of the variables found in equation (6) but adds a dummy variable, HIDELs. This additional variable is included in the analysis to allow for the potential effect on the stability and resiliency of the system of states possessing unusually high rates of mortgage loan delinquency. The states included in this category are Arizona (14.18 percent), Arkansas (18.74 percent), Colorado (13.58 percent), New Mexico (17.55 percent), Oklahoma (13.43 percent), Texas 25.72 percent), and Wyoming (9.87 percent). ${ }^{4}$

The results from estimating equations (6) through (9) by ordinary least squares (OLS) are provided in Table 2. Like the recent studies by Cebula (1994) and Chou, Cebula, and Schaffer (1994), we found a heteroskedasticity problem in these cross-section data. Accordingly, in these estimates, we have used the White (1980) correction for heteroskedasticity.

The four versions of the basic model provide a fairly consistent pattern of results. In all, 15 out of the 19 estimated coefficients exhibit the expected signs and are statistically significant at the 5 percent level or better. In addition, all four of the other coefficients have the expected signs, with three significant at the 10 percent level. The coefficient of determination ranges from 0.85 to 0.88 , so 
TABLE 2

OLS Estimates with Heteroskedasticity Correction

\begin{tabular}{lrrrr}
\hline \hline Variable Equation & $(6)$ & $(7)$ & $(8)$ & \multicolumn{1}{c}{$(9)$} \\
\hline Constant & -7.49 & -8.63 & -11.3 & -3.29 \\
rMs & +2.74 & +2.9 & +2.8 & +1.88 \\
& $(+4.39)$ & $(+6.80)$ & $(+4.09)$ & $(+3.60)$ \\
VGSPs & -0.026 & -0.029 & & -0.04 \\
& $(-1.84)$ & $(-1.94)$ & & $(-2.41)$ \\
MANs & +0.043 & & +0.047 & +0.027 \\
& $(+2.14)$ & & $(+2.05)$ & $(+1.16)$ \\
(NW/ASSET)s & +0.175 & +0.166 & +0.235 & +0.184 \\
& $(+1.93)$ & $(+2.59)$ & $(+2.92)$ & $(+3.11)$ \\
rEs & -3.00 & -2.91 & -2.63 & -2.32 \\
& $(-2.57)$ & $(-4.50)$ & $(-2.39)$ & $(-3.55)$ \\
HIDELs & & & & -2.01 \\
& & & & $(-2.54)$ \\
$R^{2}$ & 0.86 & 0.85 & 0.85 & 0.88 \\
adj R & & & & \\
F & 0.85 & 0.84 & 0.84 & 0.86 \\
\hline
\end{tabular}

*Terms in parentheses bencath coefficients are t-values.

that the model explains nearly 90 percent of the variation in the S\&L rate of return on assets.

The estimated coefficient on the variable rMs is positive and statistically significant at the 1 percent level in all four estimates. These findings provide strong evidence that the rate of return on S\&L assets is an increasing function of the mortgage portfolio yield. The estimated coefficient on the variable VGSPs is negative in all three of the estimates where it appears. In addition, it is significant at the 8 percent level in one case, at the 6 percent level in another case, and at the two percent level in the third case. These results constitute moderately strong evidence that the rate of return on S\&L assets is a decreasing function of the volatility of the average growth rate in gross state product. The estimated coefficient on variable MANs is positive in all three cases where it appears, and it is significant at the 5 percent level in two of these three cases. Thus, there is evidence that the rate of return on S\&L assets may be an increasing function of the percentage of gross state product that derives from manufacturing, at least for 1988, a year of solid economic expansion when manufacturing was prospering. 
The estimated coefficient on the (NW/ASSET)s variable is positive in all four cases and significant at the one percent level in three cases and at the 6 percent level in the fourth case. Thus, there appears to be strong evidence that the rate of return on S\&L assets is an increasing function of the capital/asset ratio. The estimated coefficient on variable rEs is negative in all four cases. In addition, it is statistically significant at the 1 percent level in three cases and at the 2 percent level in the fourth case. Hence, there is strong empirical evidence that the rate of return on S\&L assets is a decreasing function of the cost of deposits. Finally, the sign on the dummy variable HIDELs is negative and significant at beyond the 2 percent level, implying that, in those states where the delinquency rate on mortgage loans is especially high, the rate of return on S\&L assets is significantly reduced. Moreover, we also observe that the inclusion of the HIDELs dummy variable does not significantly alter the pattern of empirical findings except in the cases of variables VGSPs (which becomes more significant) and MANs (which becomes less significant).

\section{TWO ADDITIONAL ESTIMATIONS}

In this section of the study, we provide two additional OLS estimates. In the first estimate, we replace variables HIDELs and rMs in equation (9) with the variable ErMs. Variable ErMs is the product of the mortgage rate (rMs) and (1PMLs), where PMLs measures the probability of mortgage loan nonperformance in state $s$. The specification of variable ErMs follows directly from equation (1), where ErMs proxies for the term rM*(1-PML). PMLs was obtained from the Office of Thrift Supervision (1989) and is the percent of S\&L mortgage loans in state $s$ in 1988 classified as nonperforming. Estimating this modified form of equation (9) by OLS using the White (1980) correction yields:

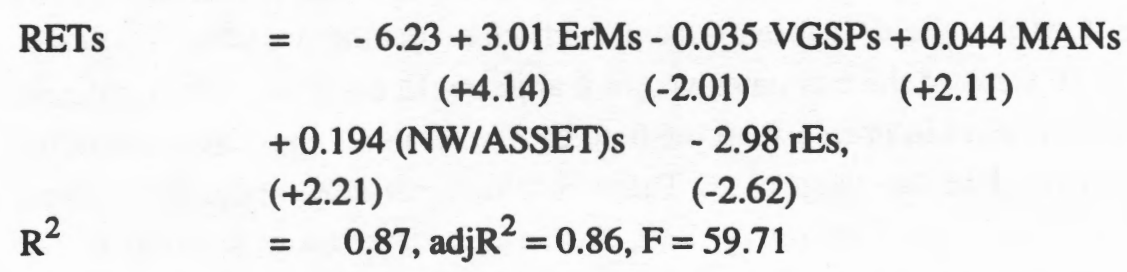

where terms in parentheses are t-values. Overall, the results shown in this modified specification are consistent with those in Table 2, with the new variable ErMs performing positively, as one might expect. In equation (10), the model explains nearly nine-tenths of the variation in the dependent variable. In addition, all of the right-hand side variables are significant at the 5 percent level or beyond. 
In the second estimation provided in this section of the study, we estimate the model underlying equation (10) for the year 1989. The year 1989 is the most recent year for which all the data are available in published form. Although it is obviously one year more recent than 1988 and thus more up to date, 1989 may be less interesting than 1988 since 1989 was a year of comparatively few S\&L closings. Contrast, for example, 1989 with its 37 S\&L closings to 1988 with its 205 S\&L closings and 1990 with its 315 S\&L closings. In any case, we provide the 1989 estimate for the reader to examine. The OLS, White (1980) corrected results are:

RETs

$$
\begin{aligned}
& =-6.62+2.97 \text { ErMs }-0.032 \text { VGSPs + 0.42 MANs } \\
& \begin{array}{lll}
(+3.96) & (-1.95) \quad(+2.05)
\end{array} \\
& +0.189 \text { (NW/ASSET)s }-2.99 \text { rEs, } \\
& (+2.19) \quad(-2.46) \\
& \mathrm{R}^{2} \quad=0.85, \operatorname{adj} \mathrm{R}^{2}=0.83, \mathrm{~F}=52.45
\end{aligned}
$$

Clearly, these results are consistent with those in Table 2 and in equation (10).

\section{v. CONCLUSION}

Based largely on a constrained S\&L profit-maximization model, this study has estimated six reduced-form equations. In all cases, the White (1980) procedure was used to correct for heteroskedasticity. The empirical findings among the different estimates are reasonably consistent. The results imply that the rate of return on S\&L assets appears to be an increasing function of (1) the mortgage portfolio yield, (2) the percentage of gross state product deriving from manufacturing, and (3) the capital/asset ratio. The rate of return on S\&L assets also appears to be a decreasing function of (4) the volatility of gross state product, (5) the cost of deposits, and (6) very high rates of mortgage delinquency.

Of these various factors, it appears that the capital requirement best qualifies as a variable over which direct public policy control can-in theory-be exercised. As observed in Barth (1991, p. 51), the prospect of losing owners' capital is the strongest force in operation to prevent unsound banking. As Barth (1991, p. 51) goes on to note, ". . inadequately capitalized institutions have every incentive to engage in high-risk activities or to gamble for resurrection." Thus, it appears that requiring more substantial, higher levels of capital may be a very appropriate, if not critical, policy for helping to ensure sound decisionmaking by S\&Ls. 


\section{ENDNOTES}

1. For simplicity, we ignore service fees on $S \& L$ provided services.

2. Implicit interest costs are ignored in this analysis for simplicity. In addition, there is also the problem of data unavailability for this variable.

3. In both 1990 and 1991, there were more S\&L failures (315 and 232, respectively) than in 1988; however, the data needed to estimate the model are not all available for either of these two years.

4. For the case of Wyoming, we rounded upwards slightly to reach the 10 percent criterion for the variable HIDELs. This is a minor modification. Dropping Wyoming from the HIDELs category does not materially alter the outcome. However, since Wyoming also had a delinquency rate in excess of 13 percent for the prior year (1987) and since 9.87 percent is essentially the same as 10 percent, we believe that including Wyoming in the HIDELs list is reasonable.

\section{REFERENCES}

Amos, Orley M., Jr. "The Regional Distribution of Bank Closings in the United States from 1982 to 1988." Southern Economic Journal. 58 (1992): 805-815.

Barth, James R. The Great Savings and Loan Debacle. Washington, D.C.: AEI Press, 1991.

Barth, James R., and R. Dan Brumbaugh, Jr. The Reform of Federal Deposit Insurance. New York: HarperBusiness, 1992.

Brumbaugh, R. Dan, Jr. Thrifts under Siege. Cambridge, MA: Ballinger Publishing Co., 1988.

Cebula, Richard J. "The Impact of Federal Deposit Insurance on Savings and Loan Failures." Southern Economic Journal. 59 (1993): 620-628.

Cebula, Richard J. "The Regional Distribution of Bank Failures in the United States: An Extension of the Amos Analysis." Southern Economic Journal. 61 (1994): 202-208.

Chou, Ray Y., Richard J. Cebula, and William Schaffer. "Determinants of Geographic Differentials in the Savings and Loan Failure Rate." Unpublished paper. 1994.

Kane, Edward J. The Gathering Crisis in Federal Deposit Insurance. Cambridge, MA: M.I.T. Press, 1985.

Kane, Edward J. "S\&Ls and Interest-Rate Reregulation: The FSLIC as an InPlace Bailout System." Housing Finance Review. 1 (1982): 219-243.

Office of Thrift Supervision. Savings and Home Financing Source Book. Washington, D.C.: U.S. Government Printing Office, 1989. 
White, Halbert. "A Heteroskedastic-Consistent Covariance Matrix Estimator and a Direct Test for Heteroskedasticity." Econometrica, 48 (1980): 817-838. 
